Published online 05 24, 2021

ISSN 2763-5392

\title{
Suicide and Transsexuality: A phenomenological- existential analysis of the meanings of experiences from case studies
}

\author{
Nicole Stephanie Moura do Nascimento ${ }^{1 *}$; Fabiane Gonçalves ${ }^{2}$ \\ 1 Postgraduate student in Mental Health Program of the Institute of Integral Medicine Professor Fernando Figueira - IMIP. Bachelor's and \\ Bachelor's degree in Psychology at the Faculty of Human Sciences of Olinda - FACHO. \\ 2 Master in Cognitive Psychology from the Federal University of Pernambuco. She is an Adjunct Professor in the Department of Psychology \\ at the Faculty of Human Sciences of Olinda. He has experience in Psychology, with emphasis on Cognitive and Clinical Psychology, working \\ mainly on the following topics: Language, Body, Gender, Development and Culture
}

E-mail adresses: nicole.psi@hotmail.com (Nicole Stephanie Moura do Nascimento), fabianemsg@facho.br (Fabiane Mônica Gonçalves), ${ }^{*}$ Corresponding author

\section{To cite this article:}

Nascimento, N.S.M.; Gonçalves, F.M. Suicide and Transsexuality: A phenomenological-existential analysis of the meanings of experiences from case studies. International Journal of Sciences. Vol. 1, No. 3, 2021, pp. 50-55. ISSN 2763-5392

Received: 05 04, 2021; Accepted: 05 07, 2021; Published: 05 24, 2021

\begin{abstract}
This study arises from the urgent need to discuss and visualize the risk of suicide for transsexuals, as it is a risk group that is not feasible. The method chosen was based on three case studies and phenomenological analysis of their narratives, using semi-structured interviews. The research was carried out in the trans space of the Hospital das Clínicas de Pernambuco (HC). The objectives were achieved to the extent that the subjects narrated their historicity identifying the meanings of the experiences lived and reconstructing in various temporalities. Therefore, we observed how much the issue of suicide is present in the narratives, because the sufferings are intense and almost unbearable, as well as it was possible to identify protective and overcoming factors. The results contribute to an in-depth look at the issues related to suffering and possibilities of suicide or life in transsexuality, in which the possibilities of this study do not end and it is expected that it can elucidate new studies from this.
\end{abstract}

Keywords: Transsexuality. Suicide, suicide. It's sense.

\section{Introduction}

This study arose from an academic-professional experience conducted at the State Center for Combating Homophobia (CECH) of Pernambuco, which during psychological interviews with transsexuals, was perceived suicide attempt in several cases. Such an alarm arose surprise and consecutive the motivation for an in-depth investigation of this phenomenon.

It is known that transsexuality and suicide are considered taboo themes around the world and accompanied by prejudices that hinder the expansion of discussions and knowledge for society. Therefore, the importance of scientific research for ethical dissemination and committed to this population.

The psychological approach chosen to sustain the seized knowledge is existential phenomenological. He considers that man is free to choose with authenticity and build his future in a dynamic process of becoming. Thus, he visualizes man as a conscious subject, capable of making intentional choices that result in the sense of his existence.
This view is rich in elements, because its values man in its dynamic, non-judgmental, changeable, comprehensive and totalitarian aspect, in which it takes into account the relationship of the being-in-the-world and the relational being (TEIXEIRA, 2006).

Therefore, it allows the understanding of transsexuality and the subjective members of the subjective to experience them, through the authenticity of the human being with his individual experiences. Merleau-Ponty (1945) describes that the world lived by the subject is his conscious experience, that among this individual reality are his intentional ways of living before his expectations.

For Frankl (1989) the human being has the need to find a meaning for his life. When the subject does not discover this meaning, he becomes fragile in the face of the adversities of life. In this sense, understanding what is behind each human being, their dreams, planning and how it affects their life says a lot about being. Thus, it is essential to know how transsexuals give meaning to their existence and how they can reconstruct their life experiences.

The conception of meaning of life and risk of suicide from 
phenomenology-existential could emerge through the narratives of the phenomenon situated in transsexual subjects, which emit languages loaded with meaning, meanings and values. The research model based on Merleau-Ponty's methodological theory made it possible to apprehend through description, reduction and interpretation, the general meaning of the propositions of the investigated with all the details of the discourse, the way of being and the contextualization of words. Then, the units of senses that drew attention and finally (re) analyzed these units to fill the real meaning of their narratives. (SIANI; CORREA; HOUSES, 2016).

In view of these aspects, the general objective was to investigate the reconstruction sings of the meanings that transsexuals narrate about suicide. The chosen method was based on three case studies and the analysis of their narratives, carried out in the trans space of the Hospital das Clínicas (HC), in which it has a space for welcoming and caring for trans people, being a reference as one of the five units in Brazil that perform surgeries to exchange sex.

Moreover, the importance of this research lies in the dialogue of these current themes that should benefit not only the target audience that are trans people, but also the population of interest and scientific academy to raise debates, research and new perspectives of intervention. Based on this, the design of this research is part of the unique universe of transsexual people in order to avoid generalizing actions, but raising reflections and especially the possibility of being better understood.

\section{Literature review}

\section{Understanding Transsexuality}

To introduce the theme of transsexuality, it is necessary to first understand previous aspects, such as human sexuality. Sexuality is part of the human constitution, in which complexity also underlies each being. So, there should be a unique pattern that fits and limits the uncover of the subjects in today's world? For a majority yes, and it concerns hetero normativity. This term is a conception that understands sexuality limited to sexual anatomy, in which it defines the being in female or male and that sexual desire must exist opposite the biological sex of birth (PETRY; MEYER, 2011).

Therefore, by identifying the straight normativity as a historical perspective of restricted apprehension of human sexuality, it allows us to perceive the reason for transsexuality to become a strangeness for some and still be seen as taboo nowadays. However, Marsiglia (2009, p.27) argues that "issues related to human sexualityare complex and pluri determined, a period that involves factors of different orders: biological, physiological, emotional, social, cultural, religious".

About sexual diversities, some basic elements such as biological sex, gender and sexual orientation are encompassed. The first refers to the physical anatomy of the genital organ that distinguishes sex in female or male and that can occur both in the case of intersex. Gender, on the other hand, is composed of a social representation that dictate modes of behavior, called feminine and masculine, that differ according to culture. And sexual orientation is the affective and sexual attraction involuntary in relation to the other person, being re known heterosexuality, homosexuality, bisexuality and others (RECIFE, 2017).

The Ministry of Health (2015) distinguishes that transsexualism is a person in which gender and social identity are opposed to the biological sex of birth. Being the trans man the one who recognizes his gender identity as male, but has the female biological sex. And the trans woman, the one whose biological sex was born male, however, recognizes her gender identity as female. That is, gender identity refers to attitudes of behavior, feeling, way of being and presenting one another.

Transsexuality is a relatively new theme in public discussions, being a reason for strangeness and prejudice by many people. For, there is difficulty in accepting those who flee from the "ideal pattern" of society, whether in religion, ethnicity and even when it involves gender identity or sexual orientation of another person. The anger discourse draws attention especially when it comes to sexuality, quite noticeable in the media, social networks and dialogues. These negative discussions end up resonating, in the way of treating LGBTQIA + added to this, the possibility of suffering transphobia, which refers to discrimination, hatred and prejudice against trans people, bringing to them difficulties such as the consolidation of rights and may cause severe emotional consequences (MINISTRY OF HEALTH, 2015).

\footnotetext{
"Human rights violations that affect people because of their sexual orientation or gender identity, real or perceived, constitute a global and consolidated pattern that causes serious concerns. The list of such violations includes extrajudicial executions, torture and ill-treatment, sexual assault and rape, invasion of privacy, arbitrary detention, denial of employment and education opportunities, and serious discrimination regarding the enjoyment of other human rights. These violations are often aggravated by other forms of violence, hatred, discrimination, and exclusion, such as those based on race, age, religion, disability, or economic, social or other status (YOGYAKARTA, 2007, p.6).
}

With regard to the semantics of the term transsexuality, Elias (2007, p.49) clarifies that "when considering the trans prefix, it refers to what transcends and what passes, associating transsexuality with a phenomenon of "transcendence" of sex beyond an anatomical destination, that is, "transit" from one sex to another". Another commonly redescribed term is transgender, which the same author (2007) explains is a useful term for transgender, transvestite or drag queens, who transform their body appearance into the gender opposite biological sex. However, these people currently prefer to be identified separately, because they have their own singularities and do not apply in generalizations.

This shows how strong the meaning of transsexuality is. That necessitate have the strength to go beyond all the difficulties and prejudices that the straight normativity generates and assume to be different, in a world where normal should be the normal of each one. Low-level labels, physical and verbal violence, harassment, hate speech and oppression are some of the challenges to be faced in the family and every social network in which the subject is inserted. As semantics bring, it is necessary to transcend many social obstacles, to live personal freedom. However, not everyone can get support to face adversity, and risks can arise, such as suicidal ideation. 
The conception of meaning and suicide under phenomenological-existential approach is considered the third great force of psychology and has its origin in the philosophical movement that investigates subjective issues of the human's experience. The central themes refer to existence, which is the way every human being acts in the world before the possibilities of choices, in the dichotomy between being its essence versus feel the anguish of not co-socially with what is expected. Phenomenology perceives each intentional experience as the being perceives it and this is where there is the suppression of the concepts for the emergence of each existential world, which can only be achieved, by avoiding systematizations that limit man (ARGERAMI-CAMON, 2002; HUSSERL, 1952).

For Frankl (1989) existential emptiness is one of the great questions of modernity. And if previously the man was a sexually frustrated, today is an existentially frustrated. It is the lack of meaning in life that compromises the human being in modernity. Thus, due to instability in the world, anyone can be susceptible to lack of sense and consecutive despair or unpreparedness for conflicting situations in life. This is where suicide can become an existential possibility to fill the possible voids in the subjects.

In this perspective, the real dimension of the suicide phenomenon is far from being understood, because the very essence of destructiveness escapes perception. However, from the historical contribution of Durkheim (1969) cited by Argerami-Camon (1997), one could reach the view that psychiatry saw suicide in the past as an individual factor. But when looking at the reactions resulting from multiple factors, it is seen that itis not a purely personal factor, when it claimed suicide to bea tragic individual denunciation of a collective crisis. Argerami-Camon (1997, p.20-21) reinforces:

\begin{abstract}
The macro society and the micro expressions of this (family) teach in a manifest or sublimated way - the models of conduct that each person adopts. If the suicidal is a death row incarcerate who carries out the fatal sentence with his own hands, then it is clear that his judges and indirect can only be "behind" the seemingly autonomous gesture that takes his life.
\end{abstract}

He also adds that "... by practicing the act of death, the suicidal man just wants to tell us that he could no longer stand it. He's talking about us, too. It confirms, on the one hand, that it could not continue to tolerate us." This brings several references to the social exclusions experienced by transsexuals, but one cannot generalize the reasons that lead people to certain acts, it is necessary to buy ender the personal motivation of the subjects (ANGERAMI-CAMON, 1997, p.21).

The complexity linked to contemporary strictive selfconducts broad, where awareness of the other is increasingly scarce, giving rise to individualism, and lack of empathy. The lack of empathy is seen as normality, in which it is very comfortable to judge that welcoming, moreover, the order of moral values seems reversed; where to do good is shameful, but to judge the other is to be part of the current machinists on war, than to have understanding and respect.

Kovács (1996, p.20) states that: " man has two great fears: of living and of dying. Living, dare, creating, brings in itself the risk, the fear of being destroyed. Not living to be at risk can give a sense of security, but it restricts the scope of life." As if the possible suffering was not enough in the face of a sometimes-toxic culture, there is also a personal clash regarding daily fears. Such conflicts are dangerous, as many consider their lives as a burden and end up not bearing it. Surge from this, the option of no longer living as the most difficult choice; or even, not being able to choose to be who you are.

Itis not appropriate to infer a generalization to suicide, because it cannot be treated simplistically to the desire for selfdestruction, nor departing specifically from social disorder. But the tendency of today's society of individuality, together with increased aggression and lack of empathy, makes it more difficult for those who have personal difficulties to rise up. With the lack of social support, profiles of emotionally weak people can suffer the consequences of human despair and/or suicidal acts with the intention of ceasing suffering, and it is necessary to deepen such issues from human experiences themselves.

\section{Methodology}

With a view to the possibility of intense suffering experienced by transsexuals, it is up to this experience to investigatein depth. Therefore, this research was based on the type of qualitative-exploratorystudy, because it answers particular questions in the social sciences, such as the human phenomena of subjectivity and relationships. It also allows familiarity with the problem and construction of hypotheses. The method used were three case studies, which have the advantage of investigating a contemporary phenomenon in its real context, exploring the phenomena (GIL, 2008).

The analysis of the results was based on the conception of phenomenological-existential approach inspired by the Merleau-Ponty theory, which has a line of investigation focused on the description of the phenomena perceived by the subjects attheageof consciousness. The method differs by understanding the human being rather than in closed conceptions, allowing the emergenceof sensitive human questions, following scientific criteria (SIANI; CORREA; HOUSES 2016).

The research occurred in the trans space located on the second floor of the Hospital das Clínicas (HC), in the university city of Recife linked to the Federal University of Pernambuco (UFPE). The unit has a space for welcoming and caring for trans people, in which five participated in the research, but only three cases were selected. Regarding the inclusion criteria: being of legal age and beingin search of psychological support. And dand exclusion: have performed the sex change or make use of controlled medications and abuse of psychoactive substances.

Data collection used as an instrument the systematic observations in which body expression, voice intonation, significant elements such as suicidal acts and thoughts, its relationship with people and especially the meaning that the subject builds about his experiences, were observed with greater attention. A socio-demographic questionnaire was also used to better understand the social of the subjects 
involved. And the open interview of depoimens chosen by the possibility and listen carefully to the subject and widen the questions according to the free course of dialogue (GIL, 2008).

In this sense, there was a centralized question about how the discovery of transsexuality occurred in their lives, to understand the account of their historicity. There were questions about the main situations experienced with difficulty in thisprocess, the most marcantmoments and howthe subjects signified their experiences. The closing question was how do they perceive themselves in the process of change today? To grasp the senses in different temporalities

Thus, this methodology favored the emergence of important contents that guarantees the research a responsible content of valorization of the stories andmeanings implied according to the narratives, related to systematic observation. Finally, the titles of the cases refer to famous transsexual characters who were chosen to represent them and thus increase the richness of this research by giving notoriety to other real cases that have rebuilt their experiences intranssexuality.

\section{Results}

\section{Case 1- Lea $T$ (One of the most important trans genre models)}

This first case occurred with a trans woman, 18 years old, resident of Recife, Catholic religion, student of Enem with average family income of two minimum wages, dating, white ethnicity, with elegance in clothing, never performed surgery, but intends sexual reassignment, nose and chin. She does progesterone hormone treatment. These initial data demonstrate a case of a student with her future study plans and a relatively average economic soc condition.

The process of discovering transsexuality took place since the age of five, in which during therapy, the psychologist presented a doll and a doll asking which one she liked to play and chose the doll, because she identified herself more. From this, she revealed that she and her mother was prepared on the theme of identity.

About the main difficulties experienced in this process, brought that suffered aggression from the brother, amigos, name-calling and a situation of transphobia. After that, she found herself naked in front of the mirror and attempted the first suicide episode at the age of 12 . He reported having paranoias of so many bad thoughts until using a razor to cut the sexual organ, in which the vision darkened and corded with a lot of blood around and huge pain in the middle of her legs without the strength to get up. "It was heavy, unintentionally, it's horrible, it gets me shivering." Reveler be ashamed, but felt no longer and regretted realizing that there were other safer ways to cope, such as surgery.

It is noted that in this case, the first sense of difficulty attributed by her was after hearing heavy words in the form of swearing by her own family and was inhibited by her way of being. According to his speech, the weight after mutilating himself was horrible and unintentionally. This denial of will to take one's own life revealed in speech takes up what ArgeramiCamon (1997) brought about suicide, that although suicide was commonly thought to be a subjective act and the subject's will, it is actually intimately implicated in how society deals as the other's way of being. After suffering transphobia, it was more difficult to survive without support and was at great risk of life.

At the age of 15, she had the first boyfriend to whom she revealed that she had been betrayed and that she was horrible, because she did everything for him. He brought not having taken his virginity with him, out of insecurity of his own body, and that currently, sometimes in sexual intercourse is disgusted by some of his body. She revealed that her current boyfriend is faithful, respectful, even accompanied in the trans space. But he has insecure and jealousy because he has experienced a lot of heavy things with ups and downs previously, and is in the process of strengthening.

In the aspect of the relationship, the breach of trust may have hindered one's acceptance and the negative way the other diminished it, contributed to the relationship of dealing with one's own body. Merleau-Ponty (1945) highlights that the perception of the other and of us goes through the perception of the body, that is, certainly, not only by the vision of the other, there, in the situation of the experience, but also of contact, in the exchange of affections.

"The most remarkable moment was to realize that I had someone beside me, that I could count, be happy, loved and the first time I felt loved." This description contains important elements in reconstructing the meaning about suicide. Once she realized she was no longer alone, but supported. Happiness expresses a new sense of being able to count on someone and feel loved. Merleau-Ponty (1945) understands that consciousness is not consciousness alone and merges into the subject and object. The case reveals that the new positive perception about oneself and life, had the help of another who valued this consciousness, since the being changes through the experiences in the world with the other.

However, he also mentioned other momentous and difficult moments, during the episode in which his father masturbated before her, but his mother did not believe, nor does he offend her with prejudice and transphobia. And her second suicide attempt, which she indicated as something very strong after fighting with her ex-boyfriend. He tried to throw himself in the window and his parents said if he tried again, they'd kill each other. She identified that it didn't help her because they didn't understand her, but prevented her from killing herself.

This moment portrays a paradox of family moment, while the father and mother did not understand the daughter's account and way, when trying to commit suicide and be saved by them, it remained initially indignation that this did not help her, but because it felt to be saved, who added that she expected more of them in the sense of support. AngeramiCamon (2002) argues that despair leads to the attempt to escape suffering and in this sense, addiction, madness and suicide are left inevitable to quiet the pain. Asked how one perceives be in this process of change, she revealed to perceive strong. He had years of leaving home, getting married, living in Curitiba and later abroad where he has ice. About the main nuclei of meaning the transsexuality indicated by her were previously of fear, doubts, insecurity and passed to safety and trust. A second intuitive analysis of these nuclei leads to the 
insight that the first senses of transsexuality collaborate with the malaise that led her to attempt suicide, but that it was rebuilt in confidence and security by being able to have support and feel loved.

\section{Case 2 -Chaz Bono (Son of singer Cher, LGBT activist)}

This case is of a trans man of 25 years, resides in Várzea / Recife, law student, with salary income of 2 minimum wages, single, brown ethnicity, never performed surgeries, but intends mastectomy and sex change. It makes use of testosterone compound. This survey initially reveals a case of an adult enrolled in higher education in a formal course and socially valued. On how the discovery of transsexuality occurred described:

"I did not fit into what has been said generically since I understand myself by people. I started to conflict with myself, I got to the phase of the masculinized lesbian, because I thought I was the one I could get to, but that's when the conflict started, it became complex.

It is possible to observe that the gender framework that normative society expected of him was never part of his reality. But by not knowing how to deal with it, he came into conflict with himself. The complex reported along with the word conflict - which was repeated in the discourse - refers to the sense of difficulties. At the age of entered the trans space and revealed that he had many fears, especially of the reaction of the mother and what might think for him to lie. In this, it shows another important sense in which family affection is factor significant in the process. Started the hormone by not supporting more and added:

"I wasn't the person who saw me in the mirror, it wasn't the pound. I
started to be happy, but this transition was very troubled because of
my mother. The fear of hurting her was the factor in delaying the
process. She had a stroke and I blamed myself too much until I
worked it out and had peace. I know that one, I tried the minimum, I
tried to make comfortable, today she understands very well,
understands that I remain the same person, because I was born wrong,
but I'm X. No use, you cannot hide what is inside. Can you imagine
if I look at you and visualize a girl and call him? Hi? So. that's it."

In this other clipping, it is possible to apprehend the conflict of image of the subject by meaning his birth with a wrong way. But for Merleau-Ponty (2006, p. 97) the subject is perceived as open to the world, in a relationship prior to any determination in which "the body is the vehicle of being in the world; having a body is for a living being to join a defined medium, to confuse with certain projects and to engage in them continuously." Thus, while he says he was born wrong, the subject inserted a new meaning to whom he states with conviction, "I am X' (his social name).

Among the main difficulties he experienced, he points out when his mother had a stroke: "my mother was my love, I blamed myself, until I couldn't take it anymore. I promised her she'd be the first person to know." In addition, he spent six years not talking to his brother, but they came to understand each other again during the process of recovery of the mother and mentioned that his brother today can see the person he is. In this situation, he revealed the care and concern for a special one. Thus, Heidegger (2013) attributes to caring as the resizing of existence, of living with the other, in which being-in-the- world is being of care, is being-with-the-other. And this may also have been another sense that contributed to the reconstruction of the senses of his experience. Other difficulties reported were in relation to social with transsexuality:

\begin{abstract}
"People marginalize, but we study, we work, we pay our bills, they think we use illicit things, and we try to break that view. Outside the house is punk, I think, it's an unusual concern. I'm not saying I'm trans. Not out of shame, because there's no need. But the person's perception changes. We go through embarrassment, prejudice comes strong. It's not lying, it's omitting. People are not prepared, the churches are not prepared, they try to suffocate us constantly. I've felt like I've been disqualified from a selection by the document. Of the 20 resumes I send, 2 comes in. People say you have no problem with gay, you have a problem with trans. It has nothing to do, your I.Q. will not decrease, it will not stop doing the activity."
\end{abstract}

This experiential account is strong and portrays the injustice and social discomfort experienced. Although it means that it omits transsexuality, but that it is not out of shame, this brings a context with doubts and insecurity. Parallel to this, the term "suffocation" felt by him deserves attention, since suffocation kills. And he used several times "couldn't take it" indicating a personal limit to bear. Therefore, although the ideation here is not explicit, it demonstrates situations that could favor this involvement.

As for the most remarkable moment was in relation to the acceptance of the mother: "today she understands and respects me more than yesterday, today I am a free man, because she loves me". Here you see the liberating question of what suffocated him. Soon, there was the possibility of moving forward, transcending and thus facing their sufferings. His final sentence was also loaded with new meanings: "we are human beings, it is something very strong, it is not an option, we have the right to live."

Revela that the subject despite having experienced difficult situations, always questioned society and followed in spite of everything. As for the cores of meaning about the transsexualities previously attributed "sadness, disappointments and hope". Hope in the past has referred to a meaning for life. Attributes the meanings of "realization, encounter with the self, happiness for being me, I was born X, I am X". The reconstruction of his sense went from sadness to fulfillment, and the hope he had previously was the key to his own overcoming of happiness with the self. It is noteworthy that he built a new meaning at the time of the interview to a phrase spoken at the beginning that was born wrong. In the end, he brought that he was born right, because he was born who he is.

\section{Case 3-Thammy Miranda (Assume to be homosexual, then be transsexual)}

This case occurred with a trans man, 25 years old, resident of the metropolitan region of Recife, spiritism religion, divorced, with training in technical education and currently works as a telemarketing operator. In this case, it was raised that he has financial stability, active spirituality, prolonged his studies beyond basic education and an active social life. In addition, it shows that transsexuals are increasingly gaining their space in work environments and religiosity.

When asked about how the discovery of transsexuality 
took place in his life, he reported that from a young school he felt different, that he liked to wear boy's clothes and identified with male characters in the drawings and films, never in the feminine. Felisberto and Baracat (2015) jointly affirm that gender identity as a personal and subjective experience represents the way feeling is expressed and acts directly in the perceptions that the subject has about himself. This shows that the dissatisfaction of those who are in parallel to the sex that were born is something remarkable since childhood.

However, at the age of 14, image conflict arose, when he was increasingly bothered by his breasts and indicated that he was the most difficult moment, in which there were doubts about what happened to him. Contrary to this, she felt good when she was praised by her family in her feminine, fragrant, hair-combed version. Oliveira (2010) explains that in adolescence there is the confusion of concepts of reality and configuration of anew self-image.

In this first moment, I find sense of doubt, in which it is possible to identify that there was an effort to be accepted by the family, in which the identification with the male identity was set aside.

In addition, he created a fake profile in which he posing as a boy to win over a friend. Both the previous situation in which she tried to please the straight normality by becoming a female gender, and having to create a false profile to conquer a person, reveals that she had to hide what she was in order to live without judgments. Such situations were remarkable in his awareness of transsexuality and it was possible to perceive the conflicting path he had to take. Rocha \& Garcia (2008) add that for adolescents to be accepted in today's world they need to be in accordance with the parameters of cultural ideation, which can be a generator of suffering and hinders selfacceptance being an emotional risk.

During an interview he brought to have few memories of his childhood moments, but that he had suffered abuse by the family and that many moments were erased. It was respected at that time and not extended due to its request. For Bouhet (1997) there may be in these situations of abuse of memory loss or denial of traumatic events as a form of defense not to deal with intense suffering.

However, the period that was discovered as a transsexual was from the age of 21 . He considered it late, but until then he never heard about transgender people. He found out from a story and everything changed. This was the most remarkable moment, realizing to be a trans man and in a short time there was a sudden change in his life. In a few days, it was reported about breast removal surgery, but realized that it is a long process due to queue waiting and started taking the hormone testosterone.

In this, he considered that "before I was shy, inhibited and could only get in touch through alcoholic beverages". But after the discovery of transsexuality, began to adapt easily to situations, stop drinking, besides realizing more comfortable and quieter. He has the dream of having children and building a family, including his social name was inspired by the name desired for a possible son. He also added that he had a lot of support from his mother throughout the process. She presented more meanings to her life by referring to plans for the future and maternal affection.
On the importance of this process, he expressed positive feelings, with sparkle in his eyes and a wide smile. He tied the sense that it was necessary to have come into the world in another way, because it resonated with the mentality he has today. "Should still be drinking, having mand lost on drugs, or being a violent sexist like the men in my family". He added that religion comforts him, namely that he was not born into the wrong body, that there is a purpose to have been born that way. In addition, among all that lived what hurt the most was the father still calling him by his old name, although he respects his time. But he has the support of his mother and brings today not to care about comments contrary to what he is.

It is noted a positive historicity although he has moments of doubt and abuse in his process of discovery, having the support of his mother comforted him to deal with the judgment of society. In addition, he joined forces with the spiritual issue also helped to give a positive sense to his experience. But based on this case, the question that remains is what are the chances of this same story having that ending if there was no necessary support and guidance? Possibly, the result is not fuss and positive and demonstrates that it is possible to face and overcome the difficulties, removing veiled forms of suicide, such as, alcohol abuse as a way out for pain generated from suffering.

On the main nuclei of meaning of transsexuality indicated by him earlier were: "courage, fears, certainties, difficulties, discoveries, anguish, hope and faith". It shows a mixture in which even at the beginning there was a negative side, but there were also indications of certainties, courage, hope and faith, which may have been paramount for the subject to have a positive evolution in the process. There was no present indicated that there was "peace, happiness, tranquility, anxiety for surgery, achievement, satisfied, complete and accomplished". The senses of peace and tranquility, besides satisfaction, demonstrate a maturity in which it suppressed existential incompleteness, giving greater appreciation to life.

\section{Conclusions}

Even intending to open the essence of the meanings presents in the interviews and being possible to reach the awareness of their historicity, the totality of the possibilities is inexhaustible and will always remain incomplete in a way that is both revealed and hidden in the results. Then, the data allow the elucidation of situations and experiential experiences that show the phenomenon as it is, without borders, but with the clarity of its perspectives.

Thus, it was possible to evidence the view that transsexuality has scientific foundations in which biological sex does not necessarily define how the subject will behave as an identity; even the absorption that suicide is not a purely subjective and individual phenomenon, but that it may have factors linked to a whole social conjuncture that also implies in these results.

It was tangible that there is a possibility for transsexuals to experience existential crises throughout their lives, for various reasons such as the lack of understanding of the 
population, along with transphobia and the constant suffering of perceiving themselves differently from biological sex. These and other issues can seriously compromise their lives by triggering emotional fragility, until they reach ideation or suicide attempts.

One of the main findings of this research is that the acceptance of family support is a factor that directly influences the perception of the subject in the face of life. In the first two cases revealed there was no support, and/or there was difficulty during acceptance, being it is the most critical cases. In addition, the relationship with the body was also brought in the historicity, since there was discontent, disgust, insecurity and desire for sexual reassignment surgeries and facial aesthetics. It was shown that the other's gaze impacts the construction of self-image and self-acceptance.

Another aspect linked to this is how much can decrease the self-esteem of transsexual subjects, because the shame, fear, insecurity, anguish, sadness and other senses attributed by them at the beginning of the discovery of transsexuality are largely linked to the attitude that society creates around their images. On the other hand, those who respect the trans subject because they are, by knowledge, skills and as a human being not limited to genitalia, tend to contribute with the confidence and consecutive positive image of these subjects for themselves. Being the relationship with the other a great factor for suffering and suicide, or for a life with meaning.

It was also revealed that although there were difficulties in their trajectories as trans subjects, even in situations of abuse, non-conformity with the body, non-acceptance of family members, prejudice, transphobia, suicidal attempt and other difficulties experienced, they overcame. They were able to reconstruct the meanings of these conflicts and weaknesses to continue to fight fora better life.

Among the positive contributions in the reconstructions are: family acceptance, affective relationship with respect, strengthening through spirituality, focus on work, professional training, appropriation of self in the therapeutic process, plans for the future and feeling loved. In this way all those negative senses were transformed into trust, security, fulfillment, happiness, encounter with the lost self, peace, tranquility and completeness. Being achievement and happiness the most repeated cores of meaning by them.

Therefore, the objectives of the research were achieved in view of the narratives of historicity, being possible to identify the sense these experiences and at the same time reconstructing in the various temporalities. It was possible to identify how suicidal ideation is an issue present even between the lines of the discourse in this audience. For suffering is intense and unbearable. But also, have be unelucidated the positive points that can strengthen them and help in the identification of protective factors to prevent the phenomenon of suicide.

Thus, the emotional experiences of transgender subjects may be of the most diverse, but the possibility of suffering and human despair is considered in this public, especially due to the high degree of intolerance by society. The results contribute to an in-depth look at issues related to suffering and possibilities of suicide or life in transsexuality. In addition to the objectives, it was possible to reflect that there is a possibility of the aspects raised appearing in other subjects in different ways, and these arrangements are a form of warning. The possibilities of this study are not finished and it is suggested the elucidation of new studies from this, with regard to therapeutic interventions for this demand.

\section{References}

[1] ANGERAMI-CAMON, V. A. Existential Psychotherapy. São Paulo: Pioneer Thomson Learning, 2002.

[2] ANGERAMI-CAMON, V. A. Suicide: Fragments of Existential Psychotherapy. São Paulo: Pioneiro, Pretextos Journal of the Undergraduate Degree in Psychology of PUC Minas v. 1, n. 2.1997.p.20-21.

[3] BOUHET, B; PERARD, D; ZORMAN, M. D. the importance of sexual abuse in France. In M. Gabel (Org.), Children who are victims of sexual abuse (pp. 29-42). São Paulo: Summus. 1997.

[4] Brazil. Ministry of Health. Resolution 466 of 12 December 2012.

[5] ELIAS, V. A. Beyond what is seen: from transsexualities to singularities in the search for body alteration. Dissertation (Master in Psychology) - Faculty of Sciences and Letters of Assisi, Paulista State University, São Paulo, 2007, p.49.

[6] FELISBERTO, J.G; BARACAT, J. TRAN Sexuality: the particularities of the Trans Man condition. Electronic Scientific Journal of Psychology. 2015. 24th Ed.

[7] FRANKL, V.E. A meaning for life: psychotherapy and humanism. Aparecida, SP: Sanctuary Publishing House. 1989.

[8] GIL, A.C. Methods and techniques of social research. 6. Ed. Atlas SA Publishing House, 2008.

[9] HEIDEGGER, M. Being and Time. Revised translation and presentation by Márcia Sá Cavalcante Schuback. 8th Ed. Petrópolis, RJ:2013.

[10] HUSSERL, E. Ideas for pure phenomenology and for a phenomenological philosophy (Vol. III - La fenomenologia y lós fundamentos de las ciências; L. Gonzales, Trad.). Mexico: UNAM. (Original published in 1952).

[11] KOVÁCS, M. J. Life and Death: Bonds of existence. Psychologist's House, 1996. p.20.

[12] MARSIGLIA, D.M. Silence and invisibility: the discriminatory attitude of teachers towards homosexuality at school. Dissertation (Master in Education) - Universidade Nove de Julho, São Paulo, 2009, p.27.

[13] MERLEAU-PONTY, M. Phenomenology of perception. Trad. Reginaldo di Pietro. Rio de Janeiro, Freitas Bastos, 1945. Original French.

[14] MERLEAU-PONTY, M The structure of the behavior. São Paulo: Martins Fontes, p. 97, 2006.

[15] MINISTRY OF HEALTH. Transsexuality and travestility in health. Brasilia, Brasilia. 2015. Available at: $<$ http://bvsms.saude.gov.br/bvs/publicacoes/transexualidade_tr avestilidade_saude.pdf $>$. Accessed: 15/01/2019.

[16] OLIVEIRA, T. A. et al. Understanding the teenager. org. 2. Ed. - Curitiba: Secretary of State for Children and Youth. Notebook 
of socio education; v. 1. 2010.

[17] PETRY, A.R; MEYER, D. E. E. Transsexuality and straight normativity: some questions for research. Texts \& Contexts, Porto Alegre, v.10, n.1, 2011. reef. LGBT citizenship guide. Secretariat for Social Development and Human Rights. Recife City Hall. 2017.

[18] ROCHA, A. P.R; GARCIA, C. A. Adolescence as a Contemporary Cultural Ideal. Psychology Journal Science and Profession. v28, n.3. 2008.

[19] SIANI, S.R; CORREA, D.A; HOUSES, A. L. Phenomenologia, phenomenological method and empirical research: the instigating universe of the construction of knowledge scanted in the life experience. Unimep Administration Journal: Piracicaba. v.14, n.1. 2016.

[20] TEIXEIRA, J.A.C. Introduction to existential psychotherapy. Psychological Analysis, Lisboa.v.24, n.3. 2006. Available in: http://www.scielo.mec.pt/pdf/aps/v24n3/v24n3a03.pdf. Accessed: 16/01/2019.

[21] YOGYAKARTA. Principles on the application of international human rights legislation in relation to sexual orientation and gender identity. 2007, p.6. Available in: http://www.dhnet.org.br/direitos/sos/gays/principios_de_yogy akarta.pdf. Accessed: 28/12/2018. 